\title{
THE EFFECTIVENESS OF CILOSTAZOL IN PATIENTS WITH GENERALIZED ATHEROSCLEROSIS
}

\author{
Lizogub V. G., \\ Doctor of Medical Science, Professor, Head of Department of Internal Medicine No4, Bogomolets \\ National Medical University, Kyiv, Ukraine, ORCID ID: https://orcid.org/0000-0003-3603-7342
}

Kupchynska O. G.,

Doctor of Medical Science, Professor, Bogomolets National Medical University, SI «National

Scientific Center «M.D. Strazhesko Institute of Cardiology, Kyiv, Ukraine,

ORCID ID: https://orcid.org/0000-0002-5615-192X

\author{
Motsak T. M., \\ PhD student, an assistant of Department of Internal Medicine No4, Bogomolets National Medical \\ University, Kyiv, Ukraine, ORCID ID: https://orcid.org/0000-0002-5545-8583 \\ Bugaytsev $O$. O., \\ Candidate of Medical Science, Bogomolets National Medical University, Kyiv, Ukraine, \\ ORCID ID: https://orcid.org/0000-0002-3513-6712
}

DOI: https://doi.org/10.31435/rsglobal_ws/30062020/7108

\section{ARTICLE INFO}

Received: 18 April 2020

Accepted: 15 June 2020

Published: 30 June 2020

\section{KEYWORDS}

generalized atherosclerosis,

blood flow rate,

myocardial ischemia,

cognitive function,

cilostazol.

\begin{abstract}
The aim of the study is to investigate the effectiveness of cilostazol in patients with generalized atherosclerosis (GAS).

A comprehensive examination of 65 male patients with proved GAS was performed (lesions of the lower extremities, carotid, mesenteric, coronary, cerebral arteries) and 28 healthy males (comparison group CG) aged over 60 years. Patients with GAS consisted of 2 groups: GAS1 - patients in addition to basic therapy received cilostazol $(\mathrm{C} ; 100$ mg 2 times per day); GAS2 - placebo. Patients with GAS showed a significant deterioration in blood flow (decrease in its volumetric blood flow - FV, increase in peak systolic velocity - PSV) in all studied arteries, episodes of myocardial ischemia according to daily ECG monitoring, decreased cognitive function (CF). In patients with GAS1 on the background of taking $\mathrm{C}$ observed improvement $(\mathrm{p}<0,001)$ blood flow in the studied arteries (increase in FV and decrease in PSV), decrease in the number and duration of episodes of myocardial ischemia ( $\mathrm{p}<0,01$ and $\mathrm{p}<0,05$, respectively), increase distances of painless and maximum walking distance $(\mathrm{p}<0,01)$, improvement of $\mathrm{CF}$. The data obtained indicate the effectiveness of $\mathrm{C}$ as part of complex therapy in patients with GAS and expediency of further research in this direction to clarify the criteria for its appointment to such patients.
\end{abstract}

Citation: Lizogub V. G., Kupchynska O. G., Motsak T. M., Bugaytsev O. O. (2020) The Effectiveness of Cilostazol in Patients with Generalized Atherosclerosis. World Science. 6(58), Vol.2. doi: 10.31435/rsglobal_ws/30062020/7108

Copyright: (C) 2020 Lizogub V. G., Kupchynska O. G., Motsak T. M., Bugaytsev O. O. This is an open-access article distributed under the terms of the Creative Commons Attribution License (CC BY). The use, distribution or reproduction in other forums is permitted, provided the original author(s) or licensor are credited and that the original publication in this journal is cited, in accordance with accepted academic practice. No use, distribution or reproduction is permitted which does not comply with these terms.

Introduction. Nowadays there are recommendations for the treatment of diseases caused by atherosclerotic lesions of individual vascular territories - coronary, cerebral, lower extremities and others. However, vascular damage by atherosclerosis has a systemic nature, resulting in often observed not only monofocal vascular damage, but the defeat of several vascular territories simultaneously. In 
this case, we are talking about generalized atherosclerosis (GAS). Conducted by Z. Khoury and coauthors more than 25 years ago, intravascular ultrasound investigation in most patients with atherosclerosis of the coronary arteries (according to coronary angiography) revealed the presence of atherosclerosis and other vessels - the aortic arch and descending aorta (81 and 91\% of the aorta), femoralis arteries and carotid arteries (72 and 77\%, respectively) [7]. These data have been confirmed by many other studies. GAS is especially common with the presence of clinical manifestations of chronic lower extremity ischemia - intermittent claudication syndrome (IC): according to the REACH register, signs of coronary heart disease (CHD) were observed in 57\% of patients with lower extremity arterial disease (LEAD) and 90\% of people with ICS. Among patients with LEAD, $60-80 \%$ of patients have hemodynamically significant lesions of coronary arteries, carotid arteries - 12-25\% [8], according to the PARTNERS study, only $13 \%$ of patients with LEAD had no signs of CHD or cerebrovascular disease. These data indicated a significant prevalence of GAS. Moreover, GAS for a long time can be clinically manifested only for one of the vascular territories, and the lesions of other vessels have a subclinical course, which prevents its timely detection. However, atherosclerotic lesions of vessels of different territories are interconnected, which is confirmed by the presence of a positive relationship between the degree of ZANK and the frequency of strokes and transient ischemic attacks (TIA) [8]. The presence of GAS negatively affects the prognosis of patients. According to the Framingham study, vascular damage in several territories may be associated with a 2-3-fold increase in the risk of cerebral circulatory disorders in patients with CHD (20-60\%), ischemic stroke (IS) (40\%) and death from CHD (2-6 times) - in patients with LEAD, as well as high mortality from cardiovascular diseases caused by atherosclerosis, which, according to epidemiological studies, in Europe exceeds 4 million annually $[8,9,13]$. Significant deterioration of the prognosis of patients with GAS determines the importance of developing approaches to their treatment.

In 2011, the European Society for Vascular Surgery (ESVS) together with the European Society of Cardiology (ESC) and the European Stroke Organization (ESO)developed, and in 2017 supplemented, recommendations for the Diagnosis and Treatment of Peripheral Arterial Diseases, which include extracranial carotid and vertebral, mesenteric, renal, upper and lower extremity arteries [15]. These guidelines also include data on the examination and treatment of patients with vascular disease in two different territories. However, research on the treatment of patients with lesions of more than two vascular territories is insufficient.

Till today many studies have proven the effectiveness of antiplatelet agents in the treatment of patients with cardiovascular disease associated with atherosclerosis of any vascular pool, and their complications, which led to inclusion these group of drugs to the appropriate local and international recommendations. Cilostazol occupies an important place in the treatment of patients with LEAD and ICS (level of evidence IA). Cilostazol (C) is a phosphodiesterase (PDE) inhibitor - selectively inhibits PDE type 3 in platelets, endothelial and smooth muscle cells. In Japan, C has been used since 1985. This drug has entered the clinical practice of America and Europe since the late 90s of the twentieth century - in 1999 the FDA, and in 2002 - the EMA (European Medicines Agency) officially allowed its use in patients with ICS. Today, $\mathrm{C}$ is considered the most effective drug in the treatment of patients with LEAD and ICS [1]. Clinical studies have also proven its effectiveness in the secondary prevention of stroke and TIA, reducing the incidence of restenosis after stenting of the arteries of the lower extremities, coronary and carotid arteries, as well as in patients with vasospastic angina $[1,2,5,11,14]$. The advantages of cilostazol compared to aspirin and other antiplatelet drugs in the development of bleeding have been proven $[2,14]$.

The experiment on rats revealed an additional effect of $\mathrm{C}$ on the background of known effects - vasodilatation, anti-inflammatory and anti-apoptosis - significant antiulcer activity of the drug, comparable to the effect of ranitidine, but without antisecretory action [6].

It should be noted that most studies have analyzed the effectiveness of $\mathrm{C}$ in its effect on one of the vascular basins, mainly in the Asian patient population, as well as the risk of heart attack or stroke. The effectiveness of this drug in patients with GAS, especially the European population, needs further research.

The aim of the study is to investigate the effectiveness of cilostazol in patients with generalized atherosclerosis.

Materials and methods. The study included 65 patients with GAS and 28 healthy males (comparison group - CG) aged 60 years and older, who gave written consent to participate in this study. Patients with GAS were randomized into two groups - GAS1 and GAS2. The GAS1 group consisted of 
32 patients with a mean age of $72.6 \pm 4.4$ years, the GAS2 group -31 patients aged $71.5 \pm 3.9$ years. The mean age of GPs was $67.3 \pm 3.5$ years. All patients of groups GAS1 and GAS2 had LEAD with manifestations of ICS and signs of atherosclerotic lesions of the femoral artery or its branches, stable CHD, including myocardial infarction suffered 48\% (15 of 32) patients GAS1 and 45\% (14 of 31) GAS2, coronary revascularization - 71.9\% (23 of 32) and 71\% (22 of 31), respectively, the presence of a history of IS - 46.9\% (15 of 32) and 41.9\% (13 of 31 ), TIA - 53.1\% (17 of 32) and 61.3\% (19 of 31); $40.6 \%$ (13 of 32) and 39\% (12 of 31) of patients with groups GAS1 and GAS2 had controlled arterial hypertension (AH), $28.1 \%$ of patients with compensated type 2 diabetes mellitus ( 9 of 32) and 32.3\% (10 of 31). Patients experienced cardiovascular complications more than six months before inclusion in the study. Patients with congestive heart failure, life-threatening arrhythmias, valvular heart disease less than six months before the start of the study cardiovascular complications, gastric and / or duodenal ulcers, persons at high risk of bleeding, including. h. thrombocytopenia, cancer, and other comorbidities requiring treatment were not included in the study. Basic treatment of patients with GAS was in accordance with existing guidelines and did not change during the study.

Examination of patients included general clinical methods (anamnesis, analysis of the Rose questionnaire in the Edinburgh modification for ICS, determination of the severity of chronic ischemia of the lower extremities according to the Fontaine-Pokrovsky classification, objective examination, echocardiography and ECG at rest). All patients included in the study were determined ankle-brachial index (ABI), the value of which less than 0.9 is not only a sign of LEAD, but also associated with a significant deterioration in prognosis [4]. In the comparison group, the values of ABI were in the range of 1.09-1.30, in patients of the GAS group - in the range of 0.54-0.87. According to the generally accepted methods, Holter ECG monitoring (HM-ECG; Cardio Sens K "HAI-MEDICA", Ukraine) and vascular dopplerography (HITACHI, ALOKA, Arietta S70) were performed. The thickness of the intima-media complex (IMT), indicators of blood flow velocity - peak systolic volume (PSV) and volumetric blood flow velocity (FV), resistance index (RI) in the arteries of different territories carotid (arteria carotis interna - ACI), mesenteric (arteria mesenterica superior - AMS), femoralis (arteria femoralis communis - AFC), tibialis (arteria tibialis posterior - ATP). In addition, painless walking distance (PWD) and maximum walking distance (MWD) were assessed in patients in the GAS group. Cognitive function was investigated according to the Montreal Cognitive Function Assessment Scale (MoCA).

Patients of the GAS1 group after the first examination in addition to the basic therapy were prescribed cilostazol ("plestazol" manufactured by the Kiev Vitamin Plant, which has certain compositional characteristics - patent №83911 from December 24, 2012 - additionally contains hypromylose, which promotes the gradual release of the active substance) $100 \mathrm{mg}$ twice a day 30 minutes before or 2 hours after meals. Only patients who took C for 12 weeks at a daily dose of 200 mg were included in the GAS1 group in this analysis. Patients in the GAS2 group in addition to baseline therapy received placebo. Repeated comprehensive examination of patients with GAS was performed after twelve weeks of taking $\mathrm{C}$ or placebo. Patients in the comparison group were examined once. There were no signs of myocardial ischemia and clinically significant cardiac arrhythmias according to HM-ECG in CG.

Statistical analysis was performed using the computer program SPSS, version 23. The nature of the distribution of variables was evaluated using the Kolmogorov-Smirnov test for one sample. The arithmetic mean $(\mathrm{M})$ and the standard error $( \pm \mathrm{m})$ were calculated for the normal distribution, and the median, lower and upper quartiles were calculated for the distribution different from the normal one. The reliability of the dynamics of the indicator was calculated by the method of pairwise variants. When comparing the values under the condition of normal data distribution, Student's t-test was used, while the Man-Whitney U-test was used when data distribution different from the normal one. The difference between the data was considered significant at $\mathrm{p}<0,05$.

Results and discussion. Patients in the GAS1, GAS2, and CG groups did not differ significantly in age. In all patients included in the study who had hypertension, on the background of basic treatment, blood pressure (BP; both systolic - SBP and diastolic - DBP) was within the target values; mean values of SBP/DBP between groups did not differ significantly ( $p>0.05$ ), amounting to $128.0 \pm 2.7 / 80.2 \pm 2.5$, $132.1 \pm 3.1 / 76.3 \pm 2.8$ and $130.5 \pm 2.9 / 76.8 \pm 2.7 \mathrm{~mm} \mathrm{Hg}$ in groups CG, GAS1 and GAS2, respectively. Hemodynamically significant heart defects were not detected in the examined patients according to echocardiography, the values of the left ventricular ejection fraction were within normal values $(>45 \%)$. 
In $37.5 \%$ ( 12 of 32 ) patients of the GAS1 group and in 32.3\% (10 of 31) of the GAS2 group who suffered from myocardial infarction, areas of hypokinesia were found, in 43.8\% (14 of 32) of the GAS1 group and 41.9\% (13 of 31) of the GAS2 group - left ventricular hypertrophy (LV). An increase in the left ventricular myocardial mass index of more than $110 \mathrm{~g} / \mathrm{m} 2$ was also found in $14.3 \%$ (4 out of 28) of CGs.

The degree of vascular lesions of the lower extremities in patients with GAS groups differed, which led to heterogeneous clinical manifestations of ICS. All patients complained of pain in the calf muscles or together the calf and thigh muscles, arising during acceleration of the gait, lifting up or long gait at a normal pace. Pain in the lower extremities, which occurred during walking, was relieved within 2-10 minutes after stopping, also the patients had no pain during rest. The patients included in the study did not have trophic changes of the lower extremities. According to the Fontaine-Pokrovsky classification - Stage IIa had 37.5\% (12 of 32) patients of the GAS1 group and 41.9\% (13 of 31) patients of the GAS2 group (patients who before the onset of pain could walk a distance of 200 to $1000 \mathrm{~m}$ ), Stage IIb - 62.5\% (20 of 32) and $58.1 \%$ (18 of 31) patients, respectively (in whom the walking distance to the onset of pain was less than $200 \mathrm{~m}$ ).

The initial condition of the arteries and blood flow in the studied vessels in patients with GAS1 were significantly worse than in the comparison group (Table 1). It is known that the most informative indicator of the characteristics of the blood supply to the organs is the rate of volumetric blood flow. As can be seen from table 1, FV in all studied arteries in patients of the GAS1 group was significantly $(\mathrm{p}<0.001)$ lower than in individuals of CG. The decrease in FV was especially significant in a.tibialis posterior (by 4 times), which is expected due to the presence of ICS in patients with GAS. In a.femoralis communis FV was less by 2.8 times, in a.mesenterica superior - by 2.4 times, in a.carotis interna by 1.9 times. In the GAS2 group, the FV values did not differ from their values in the GAS1 group, it were: in a.tibialis posterior $4.0(3.6-4.6) \mathrm{ml} / \mathrm{min}$., in a.femoralis communis -81.9 (77.0-87.7) $\mathrm{ml} / \mathrm{min}$., in a.mesenterica superior - $72.7(66.4-85.9) \mathrm{ml} / \mathrm{min}$., in a. carotis interna - 130.8 (126.1-136.8) $\mathrm{ml} / \mathrm{min}$. This confirms the presence in patients with GAS lesions of the studied vascular territories, with deterioration of blood supply relevant tissues and organs. The peak systolic velocity, on the other hand, was significantly higher $(\mathrm{p}<0.001)$ in patients of both groups with GAS compared with CG in all studied arteries. PSV values in groups GAS1 and GAS2 did not differ.

Table 1. Initial indicators of blood flow in the patients of examination groups

\begin{tabular}{|l|l|l|l|l|l|l|l|l|}
\hline \multirow{2}{*}{$\begin{array}{l}\text { Measure- } \\
\text { ments }\end{array}$} & \multicolumn{2}{|c|}{$\begin{array}{c}\text { Arteria carotis } \\
\text { interna }\end{array}$} & \multicolumn{2}{c|}{$\begin{array}{c}\text { Arteria mesenterica } \\
\text { superior }\end{array}$} & \multicolumn{2}{c|}{$\begin{array}{c}\text { Arteria femoralis } \\
\text { communis }\end{array}$} & \multicolumn{2}{c|}{$\begin{array}{c}\text { Arteria tibialis } \\
\text { posterior }\end{array}$} \\
\cline { 2 - 10 } & $\begin{array}{l}\mathrm{CG} \\
\mathrm{n}=28\end{array}$ & $\begin{array}{l}\mathrm{GAS} 1 \\
\mathrm{n}=32\end{array}$ & $\begin{array}{l}\mathrm{CG} \\
\mathrm{n}=28\end{array}$ & $\begin{array}{l}\text { GAS1 } \\
\mathrm{n}=32\end{array}$ & $\begin{array}{l}\mathrm{CG} \\
\mathrm{n}=28\end{array}$ & $\begin{array}{l}\text { GAS1 } \\
\mathrm{n}=32\end{array}$ & $\begin{array}{l}\text { CG } \\
\mathrm{n}=28\end{array}$ & $\begin{array}{l}\text { GAS1 } \\
\mathrm{n}=32\end{array}$ \\
\hline $\mathrm{FV}$, & 249.3 & 132.9 & 178.3 & 72.8 & 217.1 & 78.4 & 15.3 & 3.8 \\
$\mathrm{ml} / \mathrm{min}$ & $(135.1-$ & $(130.1-$ & $(170.1-$ & $(66.5-$ & $(156.4-$ & $(76.5-$ & $(10.1-$ & $(3.5-$ \\
& $297.5)$ & $137.0)^{* * *}$ & $183.4)$ & $86.5)^{* * *}$ & $273.6)$ & $85.2)^{* * *}$ & $19,99)$ & $4.7)^{* * *}$ \\
\hline $\mathrm{PSV}$, & 74.4 & 144.7 & 57.1 & 84.9 & 70.8 & 76.5 & 78.9 & 89.1 \\
$\mathrm{sm} / \mathrm{sec}$ & $(72.9-$ & $(130.4-$ & $(54.9-$ & $(57.6-$ & $(68.3-$ & $(73.8-$ & $(69.1-$ & $(73.8-$ \\
& $76.8)$ & $168.3)^{* * *}$ & $60.1)$ & $93.7)^{* * *}$ & $74.4)$ & $84.3)^{* * *}$ & $85.9)$ & $92.2)^{* *}$ \\
\hline RI, u.o. & 0.85 & 0.93 & 0.84 & 0.97 & 0.91 & 0.96 & 0.89 & 0.98 \\
& $(0.77-$ & $(0.92-$ & $(0.75-$ & $(0.84-$ & $(0.82-$ & $(0.74-$ & $(0.79-$ & $(0.82-$ \\
& $0.93)$ & $0.99)^{*}$ & $0.94)$ & $1.11)^{*}$ & $0.96)$ & $0.96)$ & $0.95)$ & $1.12)^{*}$ \\
\hline $\mathrm{IMC}$, & 0.96 & 1.27 & 0.97 & 1.23 & 0.99 & 1.27 & 0.99 & 1.31 \\
$\mathrm{~mm}$ & $(0.94-$ & $(1.21-$ & $(0.93-$ & $(1.17-$ & $(0.98-$ & $(1.18-$ & $(0.97-$ & $(1.22-$ \\
& $0.98)$ & $1.32)^{* * *}$ & $0.99)$ & $1.28)^{* * *}$ & $1.09)$ & $1.40)^{* * *}$ & $1.02)$ & $1.40)^{* * *}$ \\
\hline
\end{tabular}

Note. FV - volumetric blood flow; GAS - generalized atherosclerosis; IMT - an intima-media complex; $\mathrm{MnV}$ - mean average velocity; PSV - peak systolic velocity; RI - resistance index.

The dynamics of the indicator is significant: $*_{-} \mathrm{p}<0,05 ; * *_{-} \mathrm{p}<0.01 ; * *_{-} \mathrm{p}<0.001$

It is known that the peak blood flow velocity in the vessel depends on the presence and severity of vasoconstriction, and the increase in PSV corresponds to the degree of vasoconstriction. At narrowing of vessels by 55-60\% the peak systolic velocity can be both within norm, and exceed it, and at increase of a stenosis to $60-75 \%$ its accurate increase is observed. Regarding the determination of the level of carotid artery stenosis, according to the criteria of "consensus Panel Gray-Scale and 
Doppler US Criteria for Diagnosis of ICA Stenosis" with stenosis less than 50\% PSV in the internal carotid artery less than $125 \mathrm{sm} / \mathrm{sec}$, with stenosis $50-69 \%$ - is in the range of $125-230 \mathrm{sm} / \mathrm{sec}$, and with stenosis $\geq 70 \%$ exceeds $230 \mathrm{sm} / \mathrm{sec}$.

Thickening of intima-media complex of the studied arteries were observed in insignificant amount - from $14.3 \%$ (4 out of 28) to $25 \%$ (7 out of 28) in different vascular territories - in CG and in all patients with GAS. In addition, atherosclerotic plaques ( 1 to 3 ) were found in the femoral, tibial, and carotid arteries in all patients of the GAS1 and GAS2 groups. In 90.6\% (29 out of 32) and in 93.5\% (29 out of 31) patients of the GAS1 and GAS2 groups, respectively, in the mesenteric arteries.

Thus, the data of ultrasound confirmed the presence of atherosclerotic vascular lesions of the studied territories in patients with GAS.

The average score on the Montreal MoCA scale, which characterizes the state of cognitive function, in patients with GAS was significantly $(\mathrm{p}<0.05)$ lower than in CG: in the groups GAS1 it was $19.93 \pm 0.97$, in GAS2 $-19.35 \pm 0.67$ and in CG $-23.11 \pm 0.72$ points. Due to the fact that the groups did not differ significantly in age, this discrepancy can be attributed to the presence of atherosclerotic lesions of the carotid arteries that supply blood to the central nervous system (CNS) in patients with GAS, and cerebral complications - TIA and IS.

Cilostazol in a daily dose of $200 \mathrm{mg}$ was taken by 32 patients included in this analysis (group GAS1). It should be noted that initially $\mathrm{C}$ in this dose was prescribed to 37 patients, but in this analysis did not include 5 of these patients for the following reasons. In 2 of 37 patients $(5.4 \%)$ on the background of taking $\mathrm{C}$ were recorded frequent ventricular arrhythmias, in connection with which $\mathrm{C}$ was canceled. In 3 of 37 patients $(8.1 \%)$ taking C (200 mg/day) caused an increase in heart rate (HR) over 12 beats/min and feeling the heartbeat, in this regard, the dose was halved (up to $100 \mathrm{mg} / \mathrm{day}$ ). Other significant adverse effects which would require dose reduction or drug withdrawal was not recorded. However, in 4 of $32(12.5 \%)$ patients of the GAS1 group there were adverse reactions that did not affect the subsequent intake of C: $9.4 \%$ (3 of 32) patients complained of moderate headache, $3.1 \%$ ( 1 out of 32 ) - dizziness, 6.25\% (2 out of 32) noted a weakening of bowel movements within a few days. In 10 of 32 patients $(31.25 \%)$ there was a moderate increase in heart rate, which did not significantly affect the wellbeing of patients. In the GAS2 group, $6.45 \%$ of patients ( 2 out of 31 ) complained of headache while taking placebo, $3.2 \%$ ( 1 of 31) of patients complained of a brief increase in dizziness, and $3.2 \%$ complained of nausea ( 1 of 31) patients. Heart rate did not change significantly in any of the patients from the GAS2 group. More frequent occurrence of side effects on the background of $\mathrm{C}$ and drug withdrawal in our study compared with the data of a multicenter study (8.1 and $1.7 \%$, respectively) [3], which included patients with ICS, may be due to multifocal vascular lesions in our study.

Against the background of taking cilostazol (in addition to basic therapy) 93.75\% (30 of 32) patients of the GAS1 group noted a significant reduction in pain in the lower extremities, facilitating physical activity. This coincided with an increase in the painless walking distances and maximum walking, respectively, from $(172.5 \pm 41.3)$ to $(305.0 \pm 44.9) \mathrm{m}$ (by $76.8 \%$; $<<0.01)$ and from $(395,1 \pm 90.2)$ to $(563.1 \pm 85.4) \mathrm{m}$ (by $42.5 \%$; $\mathrm{p}<0.01$ ). The data is somewhat expected: most studies evaluating the effectiveness of $\mathrm{C}$ in patients with LEAD indicate an increase in walking distances against the background of its use $[1,2,3,10]$. In the GAS2 group, 16.1\% (5 of 31) patients had a reduction in lower extremity pain during walking. But PWD and MWD on average in the group did not change significantly, at the first examination it was, respectively, $171.28 \pm 37.25$ and $393.22 \pm 91.17 \mathrm{~m}$, at the second $-183.11 \pm 24.25$ and $402.36 \pm 23.18 \mathrm{~m}$ ( $\mathrm{p}>0.05$ in both cases).

Patients also reported a decrease in the number and intensity of episodes of pain in the chest and heart, which was confirmed by a decrease in the number of episodes of myocardial ischemia according to daily ECG monitoring. In the group GAS1 changes in the studied indicators under the influence of $\mathrm{C}$ were significant, in the group GAS2 the dynamics of HM-ECG was insignificant. Thus, in the group GAS1 the number of painful (PEMI) and painless episodes of myocardial ischemia (PIEMI) per day on the background of $\mathrm{C}$ decreased from $5.84 \pm 0.32$ to $3.82 \pm 0.29$ - by $34.6 \%(\mathrm{p}<0.001)$ and from $8.15 \pm 0.68$ to $6.23 \pm 0.58$ - by $23.6 \%(\mathrm{p}<0.001)$. In the GAS2 group at the first and repeated examination, the daily amount of PEMI was 5.70 \pm 0.35 and 5.41 \pm 0.23 , respectively; PIEMI - $8.11 \pm 0.67$ and $7.62 \pm 0.31$ ( $>0.05$ in both cases). Occurrence / increase in the number of ventricular arrhythmias (30-58 per day), found on reexamination in $12.5 \%$ (4 of 32) patients of the GAS1 group, did not require discontinuation of the drug.

Taking C during three months $(200 \mathrm{mg} / \mathrm{day})$ not only reduced the clinical manifestations of LEAD/ICS and coronary heart disease, but also significantly improved the blood supply of the studied 
vascular territories, as evidenced by a significant increase in volumetric $(\mathrm{p}<0.001)$ blood flow velocity in the studied arteries. Thus, FV in ACI under the influence of treatment increased by $25.0 \pm 3.7$ $\mathrm{ml} / \mathrm{min}$., in AMS - by $12.9 \pm 1.8 \mathrm{ml} / \mathrm{min}$., in AFC - by $14.9 \pm 1.9 \mathrm{ml} / \mathrm{min}$, in ATP - by $2.6 \pm 0.3 \mathrm{ml} / \mathrm{min}$. The peak systolic velocity decreased by $19.8 \pm 2.7 \mathrm{sm} / \mathrm{sec}$ in ACI $(\mathrm{p}<0.001)$, by $22.6 \pm 2.8 \mathrm{sm} / \mathrm{sec}$ in AMS ( $<<0.001)$, by $4.7 \pm 2.2 \mathrm{sm} / \mathrm{sec}$ in AFC $(\mathrm{p}<0.05)$, by $9.7 \pm 4.1 \mathrm{sm} / \mathrm{sec}$ in ATP $(\mathrm{p}<0.05)$. The thickness of IMT during this period on average in the group did not change significantly in any of the studied arteries, although in some cases there was a slight decrease in the indicator - by $0.01 \mathrm{~mm}$. It may take longer, than three months, taking $\mathrm{C}$ to reduce vascular remodeling. Such data are available, Sung Hyuk Heo and co-authors found a significant reduction in the thickness intima-media complex of the carotid arteries with five years of C intake [12]. In patients of the GAS2 group, changes in blood flow parameters were smaller and multidirectional and, on average, no significant dynamics were found in the group ( $p>0.05$ ). The increase in FV in ACI was by $9.8 \pm 8.1 \mathrm{ml} / \mathrm{min}$., in AMS - by $2.1 \pm 1.8$ $\mathrm{ml} / \mathrm{min}$., in AFC - by $6.7 \pm 4.5 \mathrm{ml} / \mathrm{min}$., in ATP - by $0.26 \pm 0.22 \mathrm{ml} / \mathrm{min}$. Significant dynamics of PSV and IMT during this period were also not revealed.

The majority of patients in the GAS1 group - 82.9\% (29 out of 35) - noted a decrease in dizziness, especially when changing body position, and headache (although in 3 patients in this group, as mentioned above, $\mathrm{C}$, on the contrary, caused a headache). Such positive dynamics may be associated with improved blood supply to the brain due to increased blood flow in the carotid arteries on the background of C. With the improvement of blood supply to the CNS and associated improvement of cognitive function on the background of $\mathrm{C}$ in patients with GAS1, not high but a significant $(\mathrm{p}<0.05)$ increase in MoCA - up to $20.97 \pm 0.59$ points. In the GAS2 group, $19.4 \%$ (6 of 31 ) and $9.7 \%$ (3 of 31 ) of patients reported a reduction in headache and dizziness, respectively. The MoCA index on average in the group did not change ( $p>0.05)$, at re-examination it was $19.49 \pm 0.58$ points.

The obtained differences in the dynamics of the clinical condition and the studied parameters in the groups GAS1 and GAS2 indicate that the changes in the indicators in the group GAS1 are due to the influence of cilostazol. Improving blood flow, increasing walking distances, and reducing the number of episodes of myocardial ischemia under $\mathrm{C}$ is associated with its known effects of the selective PDE-3 inhibitor. Specifically, with a positive effect on endothelial function with increased release of nitric oxide, improved microcirculation, counteracting the proliferation of vascular smooth muscle cells, reducing signs of inflammation, oxidative stress and areas of ischemia, initiating neovascularization of ischemic extremities, provides a clinical effect. The reduction of restenosis after stenting of arteries with the use of $\mathrm{C}$ may also be of some importance $[1,2,5]$.

Thus, the use of cilostazol in a daily dose of $200 \mathrm{mg}$ on the background of basic therapy helps to improve the well-being and clinical condition of patients with generalized atherosclerosis - to improve exercise tolerance, increase walking distance, improving blood flow in atherosclerotic vessels and cognitive function, reducing the number and duration of episodes of myocardial ischemia. The data obtained indicate the feasibility of using cilostazol as part of complex therapy in patients with GAS and further research in this direction to clarify the criteria for its appointment to such patients.

Disclosure Statement. The authors have no conflicts of interest to declare.

Author Contributions. V. Lizogub, O. Bugaytsev - research concept and project of this study; V. Lizogub, T. Motsak - materials collection and statistical data processing; V. Lizogub, O. Kupchynska, T. Motsak - literature review; writing and editing the article, formulating conclusions - V. Lizogub, O. Kupchynska. All of the authors read and contributed to this work.

\section{REFERENCES}

1. Vinogradova Yu.A. Intermittent claudication: from history to the present. RMR - 2019, №8 (11) - P.90-93 [in Russian]

2. Lizogub V.G., Kupchinska E.G., Bugaytsev A.A. Cilostazol - antiplatelet drug with great prospects Medicine of Ukraine2018 - №2 (218). -p.10-15.[in Russian]

3. Farkas Katalin, Járai Zoltán, Kolossváry Endre. Cilostazol Is Effective and Safe Option for the Treatment of Intermittent Claudication. Results of the NOCLAUD Study Orv Hetil. 2017 Jan;158(4):123-128. doi: 10.1556/650.2017.30660.

4. FowkesFG, MurrayGD, ButcherI, HealdCL, LeeRJ, ChamblessLE, et al. Ankle brachial index combined with Framingham Risk Score to predict cardiovascular events and mortality: a meta-analysis. JAMA 2008; 300:197-208 
5. Friedland S.N., Eisenberg M.J., Shimony A. Meta-analysis of randomized contolled trrails on effect of cilostazol on restenosis rates and outcomes after percutaneous coronary intervention // Am. J. Cardiol. 2012. - Vol.109 (10). - P.1397-1404

6. Helmy Moawad, Sally A El Awdan, Nada A Sallam, Wafaa I El-Eraky, Mohammed A Alkhawlani. Gastroprotective Effect of Cilostazol Against Ethanol- And Pylorus Ligation-Induced Gastric Lesions in Rats. NaunynSchmiedebergs Arch Pharmacol. 2019 Dec;392(12):1605-1616. doi: 10.1007/s00210-01901699-y. Epub 2019 Aug 1.

7. Khoury Z., Schwartz R., Gottlieb S et al. Relation of coronary artery disease to atherosclerotic disease in the aorta, carotid, and femoral arteries evaluated by ultrasound. Am J Cardiol. - 1997; 80: 1429-1433

8. 8. Lambert M. A., Belch J. J. F. Medical management of critical limb ischaemia: where do we stand today? Journal of Internal Medicine. - 2013. - Vol. 274. - P. 295-307.doi: 10.1111/joim.12102 https://angiology.com.ua/ru-issue-article-569

9. Mozaffarian D., Benjamin E., Go A. et al. Heart disease and stroke statistics-2016 update: a report from the American Heart Association. Circulation 2016; 133: e38-360

10. Roset PN. Systematic review of the efficacy of cilostazol, naftidrofuryl oxalate and pentoxifylline for the treatment of intermittent claudication (Br J Surg 2012; 99: 1630-1638). Br J Surg, 2013 Dec, 100(13): 1838. doi: 10.1002/bjs.9357.

11. Shin E.S., Lee J.H., Yoo S.Y. et al. A randomized, multicentre double-blind, placebo controlled trial to evaluate the efficacy and safety of cilostazol in patients woth vasospastic angina // Heart doi:10, 1136/heartjnl-2014-305986

12. Sung Hyuk Heo, Ji Sung Lee, Beom Joon Kim et al. Effects of cilostazol against the progression of carotid AMT in symptomatic ischemic stroke patients // J. Neurol. - 2013. - Vol.260, N1. - P.122-130

13. Townsend N., Nichols M., Scarborough P. et al. Cardiovascular disease in Europe - epidemiological update 2015. EurHeart J 2015; 36; 2696-705

14. Uchiyama S., Shinohara Y., Katahashi Y. et al. Benefit of Cilostazol in Patients with High Risk of Bleeding: Subanalysis of Cilostazol Stroke Prevention Study 2 // Cerebrovasc Dis. - 2014. - Vol.37. - P.296-303

15. 2017 ESC Guidelines on the Diagnosis and Treatment of Peripheral Arterial Diseases, in collaboration with the European Society for Vascular Surgery (ESVS): Document covering atherosclerotic disease of extracranial carotid and vertebral, mesenteric, renal, upper and lower extremity arteries Endorsed by: the European Stroke Organization (ESO)The Task Force for the Diagnosis and Treatment of Peripheral Arterial Diseases of the European Society of Cardiology (ESC) and of the European Society for Vascular Surgery (ESVS) // European Heart Journal, Volume 39, Issue 9, 01 March 2018, Pages 763-816 https://academic.oup.com/eurheartj/article/39/9/763/4095038 